Vol. 3, No. 4, December 2021, pp. 437-445, doi.org:10.52567/pjsr.v3i4.306

www.pjsr.com.pk

\title{
FEARS AND CHALLENGES IN PARENTING WITH HIV STATUS AMONG CONCORDANT COUPLES IN PAKISTAN
}

\author{
Ume Habiba \\ Ph.D. Scholar in Sociology, \\ Department of Sociology, University of Punjab, Lahore \\ habibamalik999@gmail.com \\ Farhan Navid Yousaf \\ Associate Professor, Department of Sociology, \\ Institute of Social Cultural Sciences, University of Punjab, Lahore, Pakistan. \\ drfarhan.iscs@pu.edu.pk \\ Gulshan Ara \\ Instructor, Department of Sociology, Virtual University Pakistan \\ gulshanara@vu.edu.pk
}

\begin{abstract}
$H I V$ is known as one of the most life-threatening illnesses of the contemporary era and 240,000 individuals have been estimated to live with HIV in Pakistan. The current research paper intended to find out the child-bearing and rearing concerns among HIV concordant couples. The present research has inspired a four phase model of HIV by Tasker, 1992. The researcher used a phenomenological design of qualitative research with an in-depth interview technique. We have conducted interviews with 08 HIV concordant couples by using an interview guide. Field data was analyzed through NVIVO 11 and the thematic analysis technique was used to draw the themes from field data. The four key themes of the research paper were discussed in the results and discussion section. The researchers have used only four themes mentioned as, childbearing anxieties among couples, child-rearing and family maintenance, fears for parental disclosure of HIV status to children, stigmatization \& discrimination in medical treatment in the health care system. Furthermore, HIV individuals need familial, social, and governmental support to fight against HIV and give HIV-free generation to Pakistan.
\end{abstract}

Keywords: HIV concordant couples, childbearing, child-rearing, family maintenance, fear of disclosure, stigmatization

\section{INTRODUCTION}

HIV is known as one of the most life threatening illnesses of the contemporary era and was documented in Pakistan at the beginning of 1987 (Ilyas et. al., 2011; NACP, 2021). HIV/AIDS originated as an epidemic from twenth century in Pakistan. At present, approximately 240,000 individuals have been estimated living with HIV in Pakistan (UNAIDS, 2019). There is an alarming number of HIV propagation through male spouses to females and their children which enhance the vulnerability of HIV across the world and specifically in the South Asian region because of international migration, iatrogenic transmission and drug use (Ahmed et. al., 2019). So, couples are afraid to fulfill their fertility desires and spend a happy married life with HIV. The couple entered a transition of life with responsibilities at the time of childbearing. The birth of a child reinforces marital affiliation. HIV concordant couples like normal couples were concerned about sexual life and have a fertility desire to maintain their marital relationship (Mujumdar et. al., 2018)

HIV disclosure disrupted the happy married life. Couples were happy and excited with the anticipation of having a baby because their family has completed with the arrival of a new member in the family. Couples' life has transformed with the diagnosis of HIV which crashed their dreams. HIV-infected 
Habiba, Yousaf \& Ara

families did not anticipate the future of their child with HIV status. HIV concordant couples were facing fears and challenges regarding child rearing, children's response to parental disclosure of HIV, and family maintenance as HIV parents. HIV-affected families were worried about the health and future of their families. They did not give much attention because of illness to their child's socialization (Green et. al., 2019).

HIV infected couples manage their social health crises and live healthy by deciding to disclose their HIV status to their life partner to minimize the transmission of disease to children and partner that leads to fulfill the desire for normal life and enjoy safe parenting (Thapa \& Yang, 2018: Sastre et .al., 2015).

Keeping in view the above issue, this research study intends to explore parenting concerns and challenges through using the following objectives:

\section{Objectives of the Study}

- To find out the child bearing concerns among HIV concordant couples.

- To explore the parenting experiences of HIV concordant couples.

\section{REVIEW OF LITERATURE}

Ruddick (1999) defined parenting as the state of being a parent and taking the role of mother and father. It is a three-dimensional construct such as childcare, raising the child, and maintaining a family. Hailemariam et.al. (2012) indicated the desire for children among HIV couples is a significant feature to reduce the double burden like chronic illness and maintaining a relationship in the capsule of marriage. In addition, to minimize the stress among couples, shift their interest toward their children's upbringing and try to lead a normal life.

Sastre et.al. (2015) stated that HIV couples enjoy a long and healthy life while managing HIV as a chronic disease. Little research was reported on the phenomena of parenting among HIV-infected couples. He addressed the patterns of marriage, marital relationships, and parenthood among HIVinfected couples. HIV diagnosis does not discourage active sexual life and parenting among couples. Some couples consider social and life-changing events to be a part of life and they believe to normalize their life by moving on in health crises. Couples interpreted, planned, and achieved normalcy of life in the context of HIV. Many HIV diagnosis couples are discouraged from engaging in sexual relations and having children. Parenthood and active sexual relationships are possible by attaining proper medical treatment during pregnancy. Parenting with a chronic illness is a challenging task for HIV-infected couples in terms of social and financial support.

Kanniappan et.al. (2008) stated that most researches focused on the reproductive decisions among the HIV population but few studies examined parenting desires and family life among HIV infected couples (Cooper et.al., 2007; Myer et.al., 2007; Paiva et.al., 2003; Sherr \& Barry, 2004). The expectation of becoming a parent and having children is not eliminated by HIV-positive couples. HIV-infected couples tend to express a hesitation to conceive a child because of strong social disapproval and prejudice (Segurado \& Paiva, 2007). Furthermore, the concerns of HIV-diagnosed couples are more concerned about the transmission of HIV from a parent to a child. Advance medical treatment reduces the risk of HIV transmission (Cohen et. al., 2011), some couples opt for adoption and artificial insemination as an alternative option to fulfill the desire for parenthood. Family plays a central role in childbearing and care for HIV-infected parents. Family and social support are necessary to handle serious illness management in case of assistance in treatment expenditures, child-rearing, and care.

Antle et.al. (2001) stated the anticipation of having a baby is filled with pleasure, fantasy, and apprehension. The diagnosis of HIV transformed couples' present and future life which they cannot expect. The parents grapple with the special needs of the children who were affected by their illness. Their future dreams and hope for future life have been altered with the course of HIV. Parents felt stress and burden in the process of child-raising. Usually, mothers were nurturing and tolerant towards their children with their illness, they always provided care and affection to their children. HIV couples intended to prepare their children as independent and self-sufficient because if they lose their parents then 
they will survive in the world. Parents with chronic illness tried to normalize their life for the positive upbringing of their children (Murphy, 2008; Madiba \& Matlala, 2012)

Madiba (2013) explained that parents did not disclose their HIV status to their children because of fear of death, blame, stigma, and discrimination. HIV couples have feared that children may not be able to keep secret about parents' HIV status and might lead to the family being subjected to social exclusion, stigma, and discrimination. These fears were responsible for the constant struggle by parents to keep secret their HIV status from their children, family, and friends. Health care officials provide support, guidance, and help to parents in disclosure of HIV status to their children for the management of health crises.

Mellins et.al. (2008) said that the issue of HIV disclosure of parents was a very challenging task but it is considered necessary for the parents' longer and healthier life. The revelation of parents' HIV status to their children is affiliated with better adherence to treatment from hospitals and treatment centers. It was expedient to minimize the depression and anxiety through the support of their children. The advantage of parental HIV disclose for their children is discuss safe sexual practices, improve children' wellbeing and family (Qiao et. al., 2011).

The present research paper identified the research gap on fertility desire among HIV concordant couples specifically in Pakistan and across the globe. The discussed studies have been used for gap identification and linked the phenomenon used in the studies over the years. Hasanah and Sulistiadi (2019) conducted systematic review of literature targeting married couples living with HIV/AIDS and identified only one study of Agrawal et.al (2014) specified couples at risk of HIV/AIDS in India. There is no study which constitute couples having HIV/AIDS and parenting challenges as Ali et.al (2017) done systematic analysis of 30 years prevalence of AIDS in Pakistan and identified 99 studies on the issue and found this issue in different walk of life (e.g. prisoners, refugees and foreigners, blood donors, sex workers, diseased persons and drug users) but he has not referred any study which constitute the factors targeted by the current research such as marital relationship among infected couples and parenting challenges. Mujumdar et.al (2018) through the systematic review found that the studies containing fertility desire were 12 in the whole world among HIV/AIDS infected couples but he has not mentioned any study related to Pakistani societal settings.

It is evident that little researches done on the phenomenon of parenting and challenges encountered by HIV couples that is the reason for absence of policy to address this issue. The researchers have done the qualitative research to address this gap and study the parenting experiences among seroconcordant couples. There is no study conducted on sero-concordant couples on parenting challenges among sero-concordant couples in Pakistan.

\section{THEORETICAL FRAMEWORK}

This research used a four phase model of Tasker, 1992 to explain the fears and challenges of HIV parents during child rearing and family maintenance. How parents disclose their HIV status to children and children's HIV status as well. This model is adapted from the theory of Kubler-Ross who proposed this theory in 1969. Later on, Tasker has given the four-phase model to adapt this theory and explain the HIV parents' concerns and challenges. The following figure elaborates the four-phase model of HIV. 


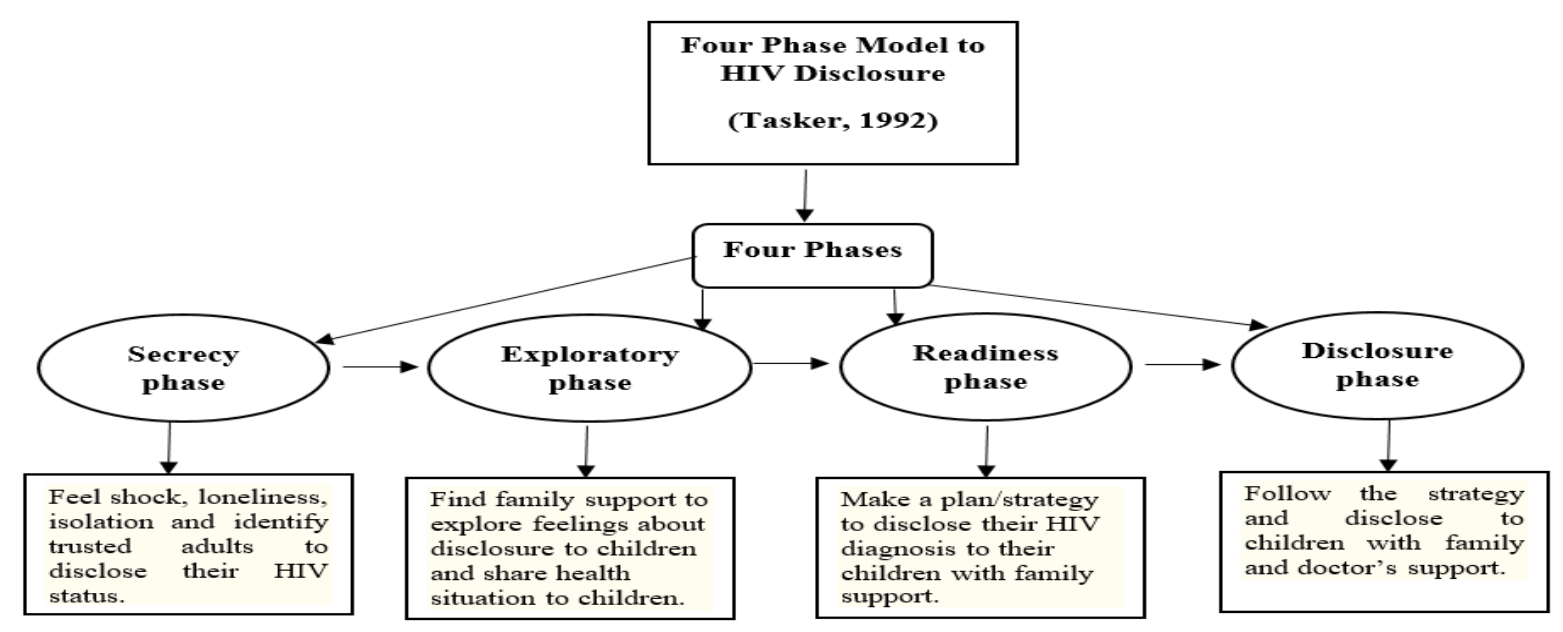

\section{METHODS AND MATERIALS}

The researcher used a phenomenological design of qualitative research with in-depth interview technique. The universe of the current study was confined to PIMS HIV center Islamabad. We have selected HIV concordant couples who belong to the Province of Punjab. The researchers have utilized purposive sampling to locate the participants. We have conducted interviews with 08 HIV concordant couples by using an interview guide. Field data was analyzed through NVIVO 11 and thematic analysis technique was used to draw the themes from field data. The researcher has collected data by herself with the ethical approval of NACP in 40 days. I have transcribed the entire interview side by side. The four key themes of the research paper are mentioned as, childbearing anxieties among couples, child rearing and family maintenance, fears for parental disclosure of HIV status to children, stigmatization \& discrimination in medical treatment in health care system were discussed in the results and discussion section.

\section{RESULTS AND DISCUSSION}

Theme 1: Childbearing Anxieties among Couples

HIV couples having a desire for the child was considered a positive sign of life and returned them to a normal phase of life. HIV individuals braced their relationship with safe sexual practices and maintaining a healthy marital relationship. HIV couples strengthen the integrity of the family and biographical disruption by planning a child by using precautions. One of the female participants shared his experience:

When I was diagnosed with HIV, my husband made the decision not to bear a child for a lifetime because he was afraid of vertical transmission of HIV from mother to child (Couple\#02).

Many HIV couples were deprived of the blessing of a healthy child with HIV because of unprofessional doctors and quacks who treated them for the sake of profit and not helped them to get back to a healthy marital life. Generally, females are reluctant to be pregnant with HIV but they have a desire for the child who makes his family complete. Women inquired about this issue with doctors who were providing counseling about childbearing. One female informant shared her initial memories of pregnancy in these words:

I am scared of childbearing after the diagnosis of HIV status but the HIV counselor encouraged me. She told me if I will use my ARV medicine during pregnancy, hopefully my child will be born with HIV negative status (Couple\#05).

\section{Theme 2: Child Rearing and Family Maintenance}

HIV couples encounter a lot of issues related to child-raising such as fear of blood contact, the transmission of disease through sharing their utensils and dread feeling when they greet them. HIV parents tried a lot to do focused parenting and enabled their children to be well-grown adults by social, emotional, and financial empowerment. HIV concordant parents did not disclose their status to their 
children because of a protecting child, Future Care Planning, Guardianship, and Preparing Affected Fathers in case of HIV infected children.

Parental Illness has influenced the children a lot. Parents tried to overcome their fears but it was useless. Parent and children association is considered vital for the grooming of children but parents are afraid of the future of children with their HIV status and fear of death as well. One male participant expressed:

When I was sick and admitted to PIMS hospital. My daughter was at home and became very scared, and now she does not want to stay without us. She has a fragile heart. So, she doesn't get affectionate with anyone (Couple\#03).

Most participants want to see their children's happiness with their eyes like normal parents and they wish to live until they will fulfill their all responsibilities but fear of death is always frightened them. One female participant shared her feeling as: "My daughter had a fear to lose their parents, and we were unable to get rid of their panic about us. I needed to live alive until my daughter got merry" (Couple\#04).

The myth of HIV transmission through touching, greeting, and sharing food is another concern of parents to their children. One male participant shared his experience:

My son was born in 2017 after the diagnosis of my HIV status. My family did not kiss him and tried to avoid him initially. When the HIV test of my son was negative, they treated him normally and took care of my son in the absence of my wife (Couple\#06).

This is the dilemma of our society who are thinking HIV is a communicable disease and is transferred through touching, sharing food, and utensils. Participants shared their experience of stigmatization and discrimination because of HIV. They are compelled to think about the discriminatory behavior of people with their children because of their HIV status. HIV parents tried to make their children socially and economically empowered to fight against the discrimination of society related to HIV beings. One male key informant discussed her fears in these words:

At the point, when I took my wife to a hospital at the time of the baby delivery. The gynecologist was not willing to deal with their case because of the HIV-positive mother. Nurses look after my wife, and my son was born in 2018. I was upset and felt hurt at that time because of the behavior of the doctor. I have decided to make my son a doctor who will not discriminate against the patients based on any disease (Couple\#01).

It was very hard for the parents of HIV-infected children to save them from the hatred of society. One female participant shared his experience as

I was afraid of my daughter's future as a girl whose mother was HIV infected. How she managed their future with HIV status? My counselor advised me, you did not take tension, just focused on the education and grooming of your daughter. You would enable your daughter enough to shut the mouth of the people who were emotionally abusing her (Couple\#02).

Childrearing is not an easy task for parents. Parents were confronting a lot of challenges in the way of raising their children and groom them as independent adults. Their focused parenting makes them being social, emotional \& financially empowered. One female shared her experience related to parenting in a special circumstance like having an affected HIV child:

I was worried about my son after the death of my 1st husband. After the second marriage, my husband adopted him as his son and took all responsibilities of him. He said I would have to groom him like a strong man and provide all facilities of life to him. We would have given him both religious and formal education to make him a pious man who follows moral obligations and proved him a well-mannered person. Insha'Allah will be a competent husband and guardian of his family in the future as an HIV being. We have to be proud of him as parents, and he will give us a respectable status with HIV (Couple\#05).

Generally, the parents disclose their HIV status in front of children when they were critically ill and they required support help and support from their children. HIV disclosure to their children aims to educate and protect them from HIV. Mostly, parents did not disclose their HIV status because they safe 
their children from stigmatization and social isolation. The rate of parents' HIV disclosure to their child was low in developing and developed countries but it varies from region to region. Parents save their children from the social and cultural consequences so they avoid and delayed their HIV disclosure.

\section{Theme 3: Fears for Parental Disclosure of HIV Status to Children}

Parents have a difficult moment in life to reveal their HIV status in front of their children. Most participants felt frightened to think about the reaction of their children when they knew the parents' HIV status. Parents were afraid to disclose their HIV status to their children because of blame, labeling, fear of disregard, and uncertainty of the child's reaction. One male participant expressed his fear as:

I was thinking all the time when my daughter knew her parents' HIV status. She would have hatred feelings and blamed us for their social isolation in society because of their parents. She felt ashamed to talk about us at any point. These thoughts afflict me all the time and I could not sleep all night. I tried a lot to get rid of these thoughts but I was helpless. My wife supported me and said, don't worry. It would not happen if you did not do anything wrong so, be comfortable (Couple\#08).

One female HIV infected mother said:

I was afraid of the reaction of my HIV-infected son when he went to know their HIV status. He would think that his parents did something wrong and transferred this curse in my blood because I was their child. He had been blamed and developed hatred feelings for his parents. He was labeled and lost his confidence in his social circle due to his HIV status. No one would think that he would be innocent, and he did not do anything wrong. He would confront stigmatization because of us. This feeling distresses me, and I blamed myself for their HIV status because of delayed acknowledgment of HIV (Couple\#07).

Most of the participants felt frightened because of the future of their children. Society cannot accept their status as a child of HIV parents because people did not accept their parents although they were the victim of this disease. In traditional societies, mistakes were not erased over time whereas people always realized the individual that you did the mistake. Realization of error is good for social control but sometimes it leads to social deviance which was harmful to society. People should support the marginalized individual who was facing hurdles because of any disease like HIV and take off the tag of stigma.

\section{Theme 4: Stigmatization \& Discrimination in Medical Treatment in Health Care System}

Stigma has shattering outcomes for HIV individuals, couples, and families such as depression, social isolation, low self-esteem, and poor health, etc. HIV-infected people were stigmatized and verbally abused. HIV-infected beings avoid access to treatment. HIV-trained staff play a crucial role in access the medical needs of HIV beings and minimized the risks of stigma and discrimination in hospitals. One female participant expressed the discriminatory behavior of doctors and medical staff with their HIV infected daughter as

My daughter was ill and admitted to a government hospital. The doctor ordered the staff

to label him as HIV positive. The label was hanging on the back of her bed. It was a very embarrassing moment for me because everyone in the hospital weirdly sees us. It's quite hurting for me as a mother because he did not do anything wrong why they have treated him like this (Couples \#04).

Mostly untrained medical staff are reluctant to treat the HIV individual however HIV is not a communicable disease. It was the dilemma of our society who considered the individual bad, not a disease. One male key informant discussed the delivery of her wife as:

"The doctor on duty did not take my wife's delivery case and left her in a critical situation because of HIV status" (Couple\#06).

\section{DISCUSSION}

HIV concordant couples like normal couples were concerning about sexual life and have a fertility desire to maintain their marital relationship. HIV concordant couples have decided to become a parent with HIV status after acquiring counseling from HIV consultants. Most of the participants experienced fear of HIV 
transmission from mother to child during pregnancy. Vance (2019) indicated that most cases were vertical transmission by mother to child through childbearing, birth, and breastfeeding. There is an alarming number of HIV propagation through male spouses to females and their children which enhance the vulnerability of HIV across the world and specifically in the South Asian region because of international migration and drug use (Emmanuel et. al., 2010). So, couples are afraid to fulfill their fertility desire and spend a happy married life with HIV (Hailemariam et. al., 2012)

HIV concordant couples were facing fears and challenges regarding child rearing, children's response to parental disclosure of HIV, and family maintenance as HIV parents. HIV-affected families were worried about the health and future of their children. Most HIV concordant couples reported that they did not give much attention because of illness to their child's socialization. Antle, et.al. (2001) indicated the joys and challenges of parenting with HIV as stigmatization, stress, and burden.

Madiba (2013) explained that parents disclose their HIV status in front of children when they are critically ill and they require support and support from their children. HIV disclosure to their children aims to educate and protect them from HIV. Generally, parents did disclose their HIV status because they safe their children from stigmatization and social isolation. The rate of parents' HIV disclosure to their child was low in developing and developed countries but it varies from region to region. Parents save their children from the social and cultural consequences so they avoid and delay their HIV disclosure.

We have explored the HIV concordant couples' experience with the health care system as HIVinfected individuals face discrimination in medical treatment because of unprofessional and untrained staff. Asadi et.al. (2018) elaborated on the positive and negative experiences of HIV individuals related to the health care sector in developing countries. There were a lack of trained medical staff leads discrimination.

\section{CONCLUSION}

Family is considered a very significant social institution of society. Parents put a lot of effort into raising their children from birth to adulthood. Childrearing can be stressful and confusing with chronic illness because you do not have any idea how you will manage this. Every parent has a wish to make their child a successful and well-mannered adult. It was quite difficult for HIV beings to do a successful upbringing of their child. Childrearing is not an easy task being an HIV parent. HIV concordant couples have a desire to peel off the label of stigmatization from their personalities.

\section{POLICY RECOMMENDATIONS}

This research has tried to highlight the need for policy interventions on HIV couples because there is only one unanimous policy for HIV individuals. There is a need for an hour to formulate proper policy to minimize the social risks of HIV couples and their parenting challenges. Because as a part of the society they have equal rights to plan and spend a normal family life. The literary efforts also provide insights into the current situation of HIV progression and highlight the gray areas in government policy.

\section{ACKNOWLEDGMENT}

This research paper was extracted from the doctoral thesis. We would like to indebted to the participants of the research who contributed to this research.

\section{CONFLICT OF INTEREST}

The researchers proclaim no potential conflicts of interest relevant to the authorship and publication of the research article.

\section{REFERENCES}

Agrawal, A., Bloom, S. S., Suchindran, C., Curtis, S., \& Angeles, G. (2014). Gender-based power and couples' HIV risk in Uttar Pradesh and Uttarakhand, north India. International perspectives on sexual and reproductive health, 40(4), 196. 
Ahmed, A., Hashmi, F. K., \& Khan, G. M. (2019). HIV outbreaks in Pakistan. The Lancet HIV, 6(7), e418.

Ali, M., Nadeem, M., Numan, M., Khalil, A. T., Maqbool, K., Yousaf, M. Z., ... \& Idrees, M. (2017). Thirty years of HIV in Pakistan: a systematic review of prevalence and current scenario. Future Virology, 12(10), 609-623.

Antle, B. J., Wells, L. M., Goldie, R. S., DeMatteo, D., \& King, S. M. (2001). Challenges of parenting for families living with HIV/AIDS. Social Work, 46(2), 159-169.

Asadi, H., Imani-Nasab, M. H., Garavand, A., Hasoumi, M., Kia, A. A., Haghi, B., \& Setoodehzadeh, F. (2018). HIV positive patients' experience of receiving health care services: A phenomenology study in Iran. The Open AIDS Journal, 12(1).

Cohen, M. S., Chen, Y. Q., McCauley, M., Gamble, T., Hosseinipour, M. C., Kumarasamy, N., ... \& Godbole, S. V. (2011). Prevention of HIV-1 infection with early antiretroviral therapy. New England Journal of Medicine, 365(6), 493-505.

Cooper, D., Harries, J., Myer, L., Orner, P., \& Bracken, H. (2007). "Life is still going on": reproductive intentions among HIV-positive women and men in South Africa. Social Science \& Medicine, 65(2), 274-283.

Emmanuel, F., Blanchard, J., Zaheer, H. A., Reza, T., \& Holte-McKenzie, M. (2010). The HIV/AIDS Surveillance Project mapping approach: an innovative approach for mapping and size estimation for groups at a higher risk of HIV in Pakistan. Aids, 24, S77-S84.

Green, E. C., Adams, A., Kennedy, C., Dlamini-Simelane, T., Ruark, A., Surkan, P., \& Nunn, A. (2019). Navigating intimate sexual partnerships in an era of HIV: dimensions of couple relationship quality and satisfaction among adults in Eswatini and linkages to HIV risk. SAHARA: Journal of Social Aspects of HIV/AIDS Research Alliance, 16(1), 10-24.

Hailemariam, T. G., Kassie, G. M., \& Sisay, M. M. (2012). Sexual life and fertility desire in long-term HIV serodiscordant couples in Addis Ababa, Ethiopia: a grounded theory study. BMC Public Health, 12(1), 1-12.

Hasanah, H., \& Sulistiadi, W. (2019). HIV/AIDS Infection among Housewives in Asia: A Systematic Review. Promoting Population Mental Health and Well-Being, 219-228.

Ilyas, M., Asad, S., Ali, L., Shah, M., Badar, S., Sarwar, M. T., \& Sumrin, A. (2011). A situational analysis of HIV and AIDS in Pakistan. Virology Journal, 8(1), 191.

Kanniappan, S. J. M. J., Jeyapaul, M. J., \& Kalyanwala, S. (2008). Desire for motherhood: exploring HIV-positive women's desires, intentions and decision-making in attaining motherhood. AIDS Care, 20(6), 625-630.

Kubler-Ross, E. (2013). On death and dying (pp. 94-99). Routledge.

Madiba, S. (2013). The impact of fear, secrecy, and stigma on parental disclosure of HIV status to children: a qualitative exploration with HIV positive parents attending an ART clinic in South Africa. Global journal of health science, 5(2), 49.

Madiba, S., \& Matlala, C. (2012). Disclosure of parental HIV positive status: what, why, when, and how parents tell their children in the era of HAART in South Africa. World Journal of AIDS, 2(03), 194.

Mellins, C. A., Brackis-Cott, E., Dolezal, C., Leu, C. S., Valentin, C., \& Meyer-Bahlburg, H. F. (2008). Mental health of early adolescents from high-risk neighborhoods: the role of maternal HIV and other contextual, self-regulation, and family factors. Journal of pediatric psychology, 33(10), 1065-1075.

Mujumdar, V., Berman, D., \& Schafer, K. R. (2018). Reproduction and fertility beliefs, perceptions, and attitudes in people living with HIV. AIDS research and treatment, 2018.

Murphy, D. A. (2008). HIV-positive mothers' disclosure of their serostatus to their young children: a review. Clinical Child psychology and psychiatry, 13(1), 105-122.

Myer, L., Morroni, C., \& Rebe, K. (2007). Prevalence and determinants of fertility intentions of HIVinfected women and men receiving antiretroviral therapy in South Africa. AIDS Patient Care and STDs, 21(4), 278-285. 
Fears and Challenges in Parenting with HIV Status among Concordant Couples in Pakistan

NACP (2021, June). Current statistics of HIV in Pakistan. Retrieved July 22, 2021, from, https://nacp.gov.pk/.

Paiva, V., Ventura Filipe, E., Santos, N., Novaes Lima, T., \& Segurado, A. (2003). The right to love: the desire for parenthood among men living with HIV. Reproductive Health Matters, 11(22), 91-100.

Qiao, S., Li, X., \& Stanton, B. (2013). Disclosure of parental HIV infection to children: a systematic review of global literature. AIDS and Behavior, 17(1), 369-389.

Ruddick, W. (1999). Parenthood: three concepts and a principle.

Sastre, F., Sheehan, D. M., \& Gonzalez, A. (2015). Dating, marriage, and parenthood for HIV-positive heterosexual Puerto Rican men: normalizing perspectives on everyday life with HIV. American Journal of Men's Health, 9(2), 139-149.

Segurado, A. C., \& Paiva, V. (2007). Rights of HIV positive people to sexual and reproductive health: parenthood. Reproductive health matters, 15(29), 27-45.

Sherr, L., \& Barry, N. (2004). Fatherhood and HIV-positive heterosexual men. HIV Medicine, 5(4), 258263.

Thapa, R., \& Yang, Y. (2018). Experiences, Emotions, and Adjustments of HIV-Infected Men in HIVConcordant Marital Relationship in Cambodia. American journal of men's health, 12(5), 12151225.

Tasker, M. (1992). How Can I Tell You? Secrecy and Disclosure with Children When a Family Member Has AIDS. Association for the Care of Children's Health, 7910 Woodmont Ave., Bethesda, MD 20814.

UNAIDS. (2019, June). Global HIV \& AIDS statistics - 2019 fact sheet. Retrieved April 15, 2020, from https://www.unaids.org/en/resources/fact-sheet.

Vance, M. A. (2019). Conflicting views in narratives on HIV transmission via medical care. Journal of the International Association of Providers of AIDS Care (JIAPAC), 18, 2325958218821961. 